\title{
THE INFLUENCE OF GEOMETRIC ELEMENTS OF THE HYDROCYCLONE ON THE EFFICIENCY OF CLEANING THE DRILLING MUD
}

\author{
Maria Georgeta POPESCU ${ }^{1}$ \\ Georgeta Claudia NICULAE ${ }^{2}$ \\ loana Gabriela STAN ${ }^{3}$ \\ Iuliana Veronica GHETIU ${ }^{4}$
}

\author{
${ }^{1}$ Assoc. Prof. U.P.G. Ploiesti, FET Departament \\ ${ }^{2}$ Lecturer, PhD U.P.G. Ploiesti, INM Department \\ ${ }^{3}$ Assist lecturer, PhD U.P.G. Ploiesti, FET Departament \\ ${ }^{4}$ Assist lecturer, PhD, U.P.G. Ploiesti, FET Departament
}

\begin{abstract}
The paper presents the algorithm for establishing the tangential, axial and radial velocities of particle cuttings from the drilling mud while the mud passes through a cyclone. The paper also includes a comparative analysis of speed values depending on the geometry of the hydro-cyclones and provides examples for various constructive types. Hydro cyclone geometry correlated with feed rate and the characteristics of the cleaning mixture influence the efficiency of the cleaning process.
\end{abstract}

\section{Introduction [1, 2]}

Hydroclones are devices used for solids control, when undesirable amounts of silt or sand may be returned to the active system. Usually are used for cleaning drilling fluids from shallow depth, when for high speeds advancement of drill bits the concentration of solids becomes exceedingly high Figure 1 is a cross-sectional diagram of a hydroclone. In figure $1: b$ is inlet pipe diameter, $\mathrm{mm} ; D_{o}-$ vortex diameter, $\mathrm{mm}, \mathrm{D}$ - barrel part diameter, mm, L - barrel part height, mm, H conical part height, $\mathrm{d}$ - apex diameter, $\mathrm{mm}$.

Through a tangentional opening into the large end of the funnel-shaped hydroclone, a centifugal pump feeds a high-volume drilling fluid. For a proper amount of pressure, the drilling fluid has a spiral motion like a tornado or cyclone. Because of the whirling of the mud, higher mass solids gets out the open bottom while returning the liquid through the top of the hydroclone.

This is o unique functional manner avilable for all hydroclones, whwther are used as desander or desilters.

A short pipe called "Vortex" gets into the hydroclone body from the top. Because of this the whirling stream is forced to start a downward movement toward a center pipe called "apex".

Because of the spiral movement of the fluid, centrifugal forces arise and large particles with higher mass will be deposited on the walls of the cone, and along the hydrocyclone axis a column of cleaning fluid and air to form, which becomes the upward movement.In proper operation, the coarse particles are removed as sprayed form and not continuous current in which case the fluid losses would be excessive.
The efficiency of hydroclone separation therefore depends on the height and diameter of the apex. If the feed pressure is in the correct range, for a standard construction of the unit, the velocity and separation capacity will decrease while the fluid density and viscosity will increase

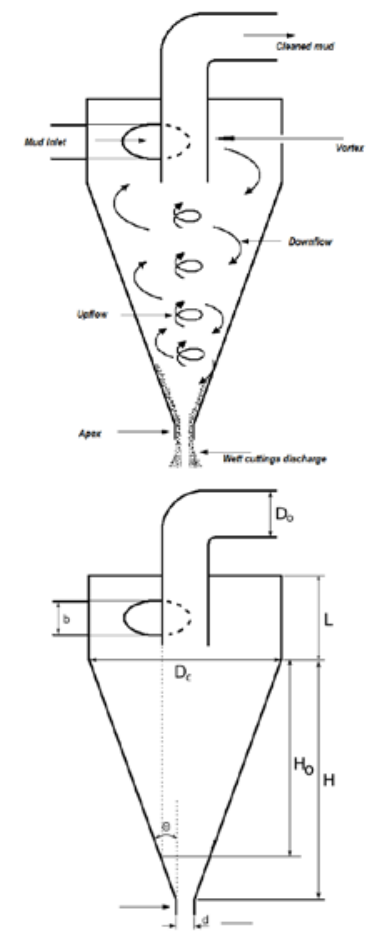

Figure 1 : cross-sectional diagram of a hydroclone [1] 
"Mircea cel Batran" Naval Academy Scientific Bulletin, Volume XIX - 2016 - Issue 2

The journal is indexed in: PROQUEST / DOAJ / Crossref / EBSCOhost / INDEX COPERNICUS / DRJI / OAJI I JOURNAL INDEX I I2OR / SCIENCE LIBRARY INDEX / Google Scholar / Academic Keys/ ROAD Open Access I Academic Resources / Scientific Indexing Services / SCIPIO / JIFACTOR

Speed values depending on the geometry of the hydro-cyclones [1,3]

Mixture of drilling fluid and detritus come into hydrocyclone has a spiral movement

The vortex help create a downflow (stronger to hydrocyclone wall) and one upward (felt on the symmetry axis of the hydrocyclone). As part of this complex movements can be identified flow velocities on the tangential, axial and radial directions of the fluid in the cyclone.

\section{a) The tangential velocity $\left(v_{t}\right)$}

The tangential velocity is the main velocity component. It determinesthe centrifugal force applied to the drilling mud.

The analysis for the tangentialvelocity starts with the analysis of the force on a unit control volume, $\Delta \mathrm{V}$, of drilling mud.

Figure 2 shows the forces acting on the control volume, $\Delta \mathrm{V}$.

The size of the control volume is:

$\Delta \mathrm{V}=w \cdot r \cdot d r \cdot d \varphi$.

The centrifugal force, $F_{c f}$, acting onthe control volume is:

$F_{c f}=\rho \cdot w \cdot r \cdot d \varphi \cdot d r \cdot \frac{w_{t}^{2}}{r}(1)$

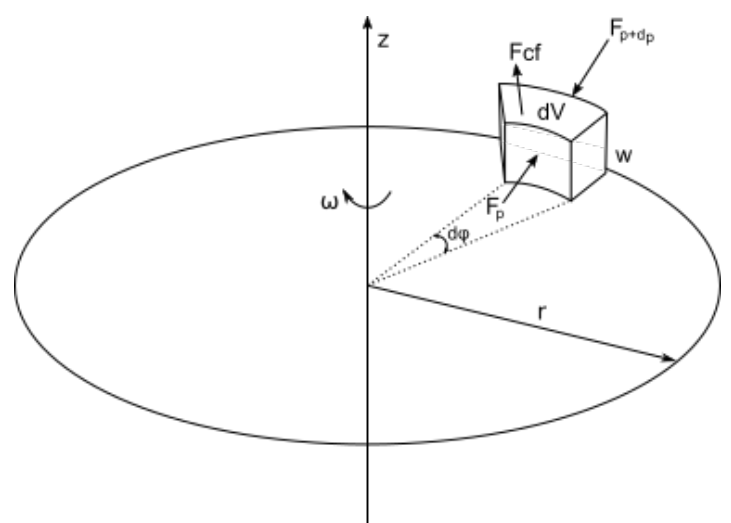

Figure 2 Distibution of centrifugal force $\boldsymbol{F}_{c f}$, on the control volume $\Delta V$

The pressure forces acting on the surfaces of the control volume are as follows

$F_{p}=p \cdot A=p \cdot w \cdot r \cdot d \varphi$

$F_{p+d p}=(p+d p) \cdot A_{d p}=(p+d p) \cdot w \cdot(r+d r)$.

$d \varphi \approx(p+d p) \cdot w \cdot r \cdot d \varphi$

(3)

Based upon the assumption that there is no radial acceleration for the drilling mud, the force balance equation for the fluid as:

$F_{c f}+F_{p}-F_{p+d p}=0$, then

$$
\begin{aligned}
& \rho \cdot w \cdot r \cdot d \varphi \cdot d r=\frac{w_{\varepsilon}^{2}}{r}+p \cdot w \cdot r \cdot d \varphi-(p+d p) . \\
& w \times r \times d \varphi=
\end{aligned}
$$

0 (4)

Because in a cyclone outer vortex, fluid has an irrotational flow, the fluid motion follows its streamline.Using the Bernoulli's equationthe pressure drop along the streamline is

$p+p \cdot \frac{v_{t}^{2}}{2}=$ constant $(5)$

The derivative of the equation 5 with respect to $r$ is

$\frac{d p}{d y}+\rho \cdot v_{t} \frac{d v_{t}}{d y}=0(6)$

From equations 4and 6 , it is obtained

$\frac{d v_{t}}{v_{t}}+\frac{d r}{r}=0$

The solution is

$v_{t} \cdot r=$ constant

This is the theoretical model for the tangential velocity distribution in the radial direction.

In the barrel part of a cyclone, the tangential velocity $\left(v_{t 1}\right)$ is equal as inlet velocity along the cyclone wall, that is

$v_{t 1}=v_{\text {in }}(9)$

In the cone part, the tangential velocity along the cyclone wall $\left(v_{t 2}\right)$ fig 2follows the model in equation 9 such as $v_{t 2} \cdot r=v_{\text {in }} \cdot R=$ constant, so $v_{t 2}=\frac{R}{r} \cdot v_{\text {in }}=\frac{R \cdot v_{i n}}{\gamma_{0}+H \tan \theta}(10)$

Since $\tan \theta=1 / 8$ (for 4inhydroclone) and $\tan \theta=$ $3 / 16$ for 8 in, then

$v_{t 2}=\frac{4 D-v_{i n}}{H+2 \cdot D}($ for 4 in $)$

$v_{t 2}=\frac{\mathbb{Q} \cdot D \cdot v_{i n}}{\mathrm{a} H+4 \cdot D} \quad$ (for8 in)

\section{b) Axial Velocity $\left(v_{a}\right)$}

In the barrel part $\left(v_{a 1}\right)$

In the barrel part, the fluidflow rate is constant in the outervortex; as a result, the axial velocity $\left(v_{a 1}\right)$ can be determined as follows:

$v_{a 1} \cdot\left(\frac{\pi \cdot D^{2}}{4}-\frac{\pi \cdot D_{0}^{2}}{4}\right)=v_{\text {in }} \times \frac{D^{2}}{8}$

for the constant flow rate.

Using the standard $D_{o}$ dimension for 4 in and 8in cyclone designs, the axial velocity is 
"Mircea cel Batran" Naval Academy Scientific Bulletin, Volume XIX - 2016 - Issue 2

The journal is indexed in: PROQUEST / DOAJ / Crossref / EBSCOhost / INDEX COPERNICUS / DRJI / OAJI I JOURNAL INDEX I I2OR / SCIENCE LIBRARY INDEX / Google Scholar / Academic Keys/ ROAD Open Access I Academic Resources / Scientific Indexing Services / SCIPIO / JIFACTOR

$v_{a 1}=\frac{2 \cdot v_{i n}}{a \cdot \pi}($ For 4 in and 8in)

In the cone part $\left(v_{a 2}\right)$

In the cone part of a cyclone, the fluidflow leaks from outervortex to inner vortex flowing a model as:

$$
Q=Q_{\text {in }} \times \frac{H}{H_{02}}
$$

So, the axial velocity in the cone part is

$v_{a 2}=-\frac{Q_{m}}{A_{a}}=\frac{-Q_{i n}}{\pi \cdot\left(R-Y_{0}\right)} \times \frac{1}{\frac{R-r_{0}}{H_{02}} \cdot H+2 \gamma_{0}}$

Based upon $\mathrm{H}_{02}$ dimension (the effective length in the cone part figure 1 ) and equation 12 , the axial velocities for 4 in and8 in designs are as follows:

$$
\begin{aligned}
& v_{a 2}=\frac{4 n D-v_{l n}}{(H+4-D) \cdot \pi}(\text { for4 in) } \\
& v_{a 2}=\frac{g \cdot D \cdot v_{i n}}{(a H+\mathbb{B} \cdot D) \cdot \pi}(\text { for8 in })
\end{aligned}
$$

\section{c)Radial Velocity $\left(v_{r}\right)$}

It was assumed that the radial velocity is zero in the barrel part. In the cone partof a cyclone the radial velocity can be determined by

$v_{r 2}=v_{z 2} * \tan \theta$, so

$v_{r 2}=\frac{D \cdot v_{\text {in }}}{(2 H+Q \cdot D) \cdot \pi}($ for4 in $)$

$v_{r 2}=\frac{a \cdot D \cdot V_{\ln }}{(6 H+16 \cdot D) \cdot \pi}$ (for8 in)

Optimization of working process $[1,2]$

Head is related to pressure as follows

$H_{\mathrm{p}}=\frac{p}{\gamma}$

The flow is related to geometrical dimensions of cyclone as follows

$Q=10^{-6}\left(5,05-0,0287 D_{0}\right) b D_{o}(p / \rho)^{1 / 2}$

where:p - feed pressure, îndaN/ $\mathrm{cm}^{2} ; \rho-$ mud density, în $\mathrm{g} / \mathrm{cm}^{3}$.

The above relation is available for $\varphi=15 \ldots 20^{\circ}$ and $D_{c} \leq 400 \mathrm{~mm}$

The length of the barrel part is

$L=(0,9 \ldots 1) D$

Many hydroclone devices (check with the manufacturer) are designed for about $75 \mathrm{ft}$ (22.9 m) of head at the inlet manifold. Since mud weight is a factor in the above equation, the pressure required to produce the proper amount of head will vary with mud weight.

Head should be measured at the manifold inlet, since it will decrease between the pump and the hydroclone manifold.

Inadequate head will result in smaller volumes of mud being processed and a larger-than-desired cut point.

For example, when the head is $13.7 \mathrm{~m}$ instead of $22.9 \mathrm{~m}$, a 4-in. (101.6-mm) hydroclone will process only $151.4 \mathrm{~L} / \mathrm{min}$ instead of $189.3 \mathrm{~L} / \mathrm{min}$, and the cut point will be 55 microns instead of 15 microns. Excessive head also is detrimental, with most solids carried back into the mud system.

The efficiency of different construction typeshidrociclone is going to be calculated for a rig of 320 tf hook

For a 4 in hidroclone, with $\mathrm{D}=101,6 \mathrm{~mm}, \quad b=30$ $\mathrm{mm}$ and $D_{0}=42 \mathrm{~mm}$, the results are presented in tabel no. 1 and for $\mathrm{b}=30 \mathrm{~mm}, D_{o}=38 \mathrm{~mm}$ in tabel no.2.

Table no. 1

\begin{tabular}{|l|l|l|l|l|}
\hline & \multicolumn{2}{|l|}{$\begin{array}{l}\text { Minimum } \\
\text { operating } \\
\text { pressure, } \mathrm{kPa}\end{array}$} & \multicolumn{2}{|c|}{$\begin{array}{l}\text { Maximum } \\
\text { operating } \\
\text { pressure, } \mathrm{kPa}\end{array}$} \\
\hline & \multicolumn{2}{|c|}{210} & \multicolumn{2}{c|}{350} \\
\hline $\begin{array}{l}\text { Fluid } \\
\text { density } \\
\mathrm{kg} / \mathrm{m}^{3}\end{array}$ & 1100 & 1500 & 1100 & 1500 \\
\hline $\begin{array}{l}\text { Flow } \\
\mathrm{m}^{3} / \mathrm{h}\end{array}$ & 24,096 & 20,634 & 31,107 & 26,639 \\
\hline $\begin{array}{l}\text { Inlet } \\
\text { velocity, } \\
\text { m/s }\end{array}$ & 16,4 & 17 & 15 & 15,6 \\
\hline $\begin{array}{l}\text { Axial } \\
\text { velocity, } \\
\text { m/s }\end{array}$ & 2,95 & 3,09 & 2,72 & 2,85 \\
\hline $\begin{array}{l}\text { Tangential } \\
\text { velocity, } \\
\text { m/s }\end{array}$ & 13,1 & 13,6 & 12 & 12,5 \\
\hline $\begin{array}{l}\text { Radial } \\
\text { velocity, } \\
\text { m/s }\end{array}$ & 0,36 & 0,38 & 0,34 & 0,35 \\
\hline
\end{tabular}


"Mircea cel Batran" Naval Academy Scientific Bulletin, Volume XIX - 2016 - Issue 2

The journal is indexed in: PROQUEST / DOAJ / Crossref / EBSCOhost / INDEX COPERNICUS / DRJI / OAJI I JOURNAL INDEX I I2OR / SCIENCE LIBRARY INDEX / Google Scholar / Academic Keys/ ROAD Open Access I Academic Resources / Scientific Indexing Services / SCIPIO / JIFACTOR

Table no. 2

\begin{tabular}{|l|l|l|l|l|}
\hline & \multicolumn{2}{|c|}{$\begin{array}{l}\text { Minimum } \\
\text { operating } \\
\text { pressure, } \mathrm{kPa}\end{array}$} & \multicolumn{2}{|c|}{$\begin{array}{l}\text { Maximum } \\
\text { operating } \\
\text { pressure, } \mathrm{kPa}\end{array}$} \\
\hline & \multicolumn{2}{|c|}{210} & \multicolumn{2}{c|}{350} \\
\hline $\begin{array}{l}\text { Fluid } \\
\text { density } \\
\mathrm{kg} / \mathrm{m}^{3}\end{array}$ & 1100 & 1500 & 1100 & 1500 \\
\hline $\begin{array}{l}\text { Flow } \\
\mathrm{m}^{3} / \mathrm{h}\end{array}$ & 22,425 & 19,227 & 28,985 & 24,821 \\
\hline $\begin{array}{l}\text { Inlet } \\
\text { velocity, } \\
\mathrm{m} / \mathrm{s}\end{array}$ & 16,4 & 17 & 15 & 15,6 \\
\hline $\begin{array}{l}\text { Axial } \\
\text { velocity, } \\
\text { m/s }\end{array}$ & 2,95 & 3,09 & 2,72 & 2,85 \\
\hline $\begin{array}{l}\text { Tangential } \\
\text { velocity, } \\
\text { m/s }\end{array}$ & 13,1 & 13,6 & 12 & 12,5 \\
\hline $\begin{array}{l}\text { Radial } \\
\text { velocity, } \\
\text { m/s }\end{array}$ & 0,36 & 0,38 & 0,34 & 0,35 \\
\hline
\end{tabular}

For a 8 in hidroclone, with $\mathrm{D}=203,2 \mathrm{~mm}, \quad b=38$ $\mathrm{mm}$ and $D_{o}=67 \mathrm{~mm}$, the results are presented in tabel no. 3 and for $\mathrm{b}=38 \mathrm{~mm}, D_{o}=60 \mathrm{~mm}$ in tabel no.4.

Tabelul 3

\begin{tabular}{|l|l|l|l|l|}
\hline & \multicolumn{2}{|l|}{$\begin{array}{l}\text { Minimum } \\
\text { operating } \\
\text { pressure, } \mathrm{kPa}\end{array}$} & \multicolumn{2}{|c|}{$\begin{array}{l}\text { Maximum } \\
\text { operating } \\
\text { pressure, } \mathrm{kPa}\end{array}$} \\
\hline & \multicolumn{2}{|c|}{210} & \multicolumn{2}{|c|}{350} \\
\hline $\begin{array}{l}\text { Fluid } \\
\text { density } \\
\mathrm{kg} / \mathrm{m}^{3}\end{array}$ & 1100 & 1500 & 1100 & 1500 \\
\hline $\begin{array}{l}\text { Flow } \\
\mathrm{m}^{3} / \mathrm{h}\end{array}$ & 39,602 & 33,913 & 51,126 & 43,782 \\
\hline $\begin{array}{l}\text { Inlet } \\
\text { velocity, } \\
\text { m/s }\end{array}$ & 15,7 & 16 & 14 & 14,8 \\
\hline $\begin{array}{l}\text { Axial } \\
\text { velocity, } \\
\text { m/s }\end{array}$ & 2,27 & 2,39 & 2,09 & 2,16 \\
\hline $\begin{array}{l}\text { Tangential } \\
\text { velocity, } \\
\text { m/s }\end{array}$ & 9,32 & 9,85 & 8,61 & 8,75 \\
\hline $\begin{array}{l}\text { Radial } \\
\text { velocity, } \\
\text { m/s }\end{array}$ & 0,41 & 0,44 & 0,39 & 0,36 \\
\hline
\end{tabular}

Table 4

\begin{tabular}{|l|l|l|l|l|}
\hline & \multicolumn{2}{|l|}{$\begin{array}{l}\text { Minimum } \\
\text { operating } \\
\text { pressure, } \mathrm{kPa}\end{array}$} & \multicolumn{2}{l|}{$\begin{array}{l}\text { Maximum } \\
\text { operating } \\
\text { pressure, } \mathrm{kPa}\end{array}$} \\
\hline & 210 & 350 & \\
\hline $\begin{array}{l}\text { Fluid } \\
\text { density } \\
\mathrm{kg} / \mathrm{m}^{3}\end{array}$ & 1100 & 1500 & 1100 & 1500 \\
\hline $\begin{array}{l}\text { Flow } \\
\mathrm{m}^{3} / \mathrm{h}\end{array}$ & 37,743 & 32,321 & 48,726 & 41,726 \\
\hline $\begin{array}{l}\text { Inlet } \\
\text { velocity, } \\
\text { m/s }\end{array}$ & 15,7 & 16 & 14 & 14,8 \\
\hline $\begin{array}{l}\text { Axial } \\
\text { velocity, } \\
\text { m/s }\end{array}$ & 2,27 & 2,39 & 2,09 & 2,16 \\
\hline $\begin{array}{l}\text { Tangential } \\
\text { velocity, } \\
\text { m/s }\end{array}$ & 9,32 & 9,85 & 8,61 & 8,75 \\
\hline $\begin{array}{l}\text { Radial } \\
\text { velocity, } \\
\text { m/s }\end{array}$ & 0,41 & 0,44 & 0,39 & 0,36 \\
\hline
\end{tabular}

From drilling mud cleaning system scheme is found that are six cyclone batteries operating in parallel.

Optimal flow rate for a battery of six cyclones, 4 in, each of the cases considered are shown in table 5.

Table 5

\begin{tabular}{|l|l|l|l|l|}
\hline & \multicolumn{2}{|l|}{$\begin{array}{l}\text { Minimum operating } \\
\text { pressure, } \mathrm{kPa}\end{array}$} & $\begin{array}{l}\text { Maximum } \\
\text { operating } \\
\text { pressure, } \mathrm{kPa}\end{array}$ \\
\hline & 210 & 350 \\
\hline $\mathrm{b}$ & 30 & 30 & 30 & 30 \\
\hline$D_{o}$ & 42 & 38 & 42 & 38 \\
\hline debitul & 123,805 & 115,359 & 186,644 & 173,910 \\
\hline
\end{tabular}

Optimal flow rate for a battery of six cyclones, 8 in, each of the cases considered are shown in Table 6

Table 6

\begin{tabular}{|l|l|l|l|l|}
\hline & \multicolumn{2}{|l|}{$\begin{array}{l}\text { Minimum } \\
\text { operating } \\
\text { pressure, } \mathrm{kPa}\end{array}$} & \multicolumn{2}{l|}{$\begin{array}{l}\text { Maximum } \\
\text { operating } \\
\text { pressure, } \mathrm{kPa}\end{array}$} \\
\hline & 210 & 350 & \multicolumn{2}{l|}{} \\
\hline $\mathrm{b}$ & 30 & 30 & 30 & 30 \\
\hline $\mathrm{D}_{\mathrm{o}}$ & 42 & 38 & 42 & 38 \\
\hline $\begin{array}{l}\text { Debitul, } \\
\mathrm{m}^{3} / \mathrm{h}\end{array}$ & 203,478 & 193,926 & 306,755 & 292,354 \\
\hline
\end{tabular}


"Mircea cel Batran" Naval Academy Scientific Bulletin, Volume XIX - 2016 - Issue 2

The journal is indexed in: PROQUEST / DOAJ / Crossref / EBSCOhost / INDEX COPERNICUS / DRJI / OAJI I

JOURNAL INDEX I I2OR / SCIENCE LIBRARY INDEX / Google Scholar / Academic Keys/ ROAD Open Access I Academic Resources / Scientific Indexing Services / SCIPIO / JIFACTOR

\section{CONCLUSIONS}

The efficiency of cleaning cuttings from the drilling fluid is influenced by the inlet speed of the fluid and correlation fluid density / clean debit.

The tangential component of the velocity of the fluid in the hydrocyclone is dependent on velocity inlets of drilling mud in the hydrocyclone and a hydrocyclone diameter of the barrel part and the height of cone part The capacity of 4 in hirdoclone with $d_{i}=30 \mathrm{~mm}$ and $d_{\mathrm{e}}=42 \mathrm{~mm}$, operating at pressures $\mathrm{p}=210 \mathrm{kPaandfor}$ a fluid with density $\rho=(1100 \ldots 1500) \mathrm{kg} / \mathrm{m}^{3}$ is in the range: $\mathrm{Q}_{c} 1=(20,634 \ldots 31,107) \mathrm{m} 3 / \mathrm{h}$

The capacity of 8 in hirdoclone with $d_{i}=38 \mathrm{~mm}$ and $d_{e}=67 \mathrm{~mm}$, operating at pressures $p=210 \mathrm{kPa}$ and $\mathrm{p}=350 \mathrm{kPa}$, and for a fluid with density $\rho=(1100 \ldots 1500) \mathrm{kg} / \mathrm{m}^{3}$ is in the range: $\mathrm{Qc} 1=(33,913 \ldots 51,126) \mathrm{m}^{3} / \mathrm{h}$ Results calculation of optimal flow for the following casesare:

4in hidroclone:

- $\quad$ case $1-d_{i}=30 \mathrm{~mm}, d_{e}=42 \mathrm{~mm}=>Q_{0}=123,805 \ldots 186,644 \mathrm{~m}^{3} / \mathrm{h}$;

- $\quad$ case $2-d_{i}=30 \mathrm{~mm} ; d_{e}=38 \mathrm{~mm}=>Q_{0}=115,359 \ldots 173,910 \mathrm{~m}^{3} / \mathrm{h}$;

8in hidroclone:

- $\quad$ case $1-d_{i}=38 \mathrm{~mm} ; d_{e}=67 \mathrm{~mm}=>Q_{0}=203,478 \ldots 306,755 \mathrm{m3} / \mathrm{h}$;

- $\quad$ case $2-d_{i}=38 \mathrm{~mm} ; d_{e}=60 \mathrm{~mm}=>Q_{0}=193,926 \ldots 292,354 \mathrm{~m}^{3} / \mathrm{h}$.

\section{BIBLIOGRAPHY}

[1] Popescu, M., Fluide de foraj şi cimenturi de sondă, Editura Universităţii din Ploieşti, 2002

[2] Popovici, Al., Niculae, C., s.a., Calculul şi construcţia utilajului pentru forajul sondelor de petrol, Editura Universităţii din Ploieşti, 2005

[3] Lingjuan Wang-Li, Theoretical study of cyclone design, North Carolina State University, 2004 